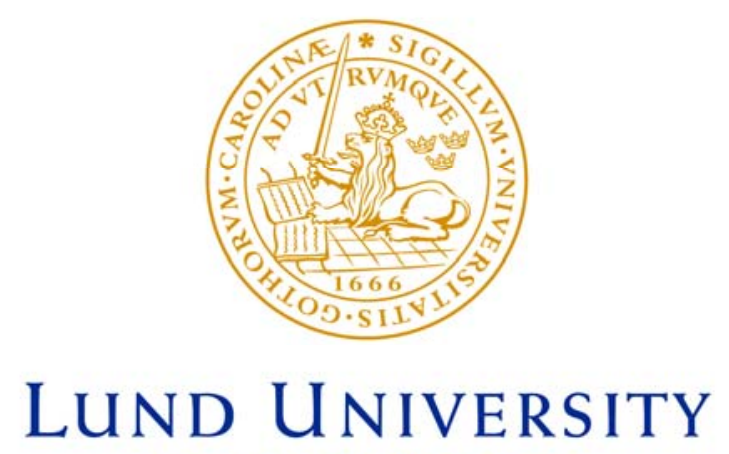

Faculty of Medicine

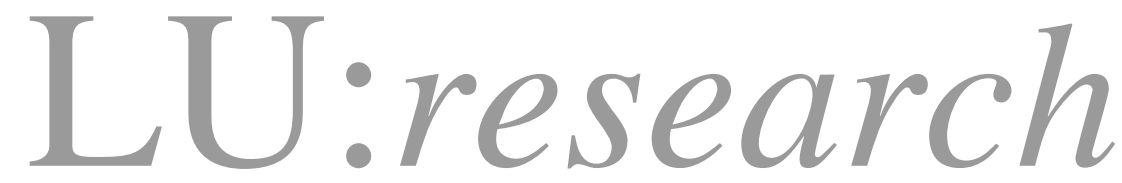

Institutional Repository of Lund University

This is an author produced version of a paper published in Immunogenetics. This paper has been peer-reviewed but does not include the final publisher proof-corrections or journal pagination.

Citation for the published paper:

Gabdoulkhakova, Aida and Henriksson, Gunnel and Avkhacheva, Nadezhda and Sofin, Alexander and Bredberg, Anders.

"High rate of mutation reporter gene inactivation during human T cell proliferation"

Immunogenetics, 2007, Vol: 59, Issue: 2, pp. 135-43.

http://dx.doi.org/10.1007/s00251-006-0180-8

Access to the published version may require journal subscription.

Published with permission from: SpringerLink 


\title{
High rate of mutation reporter gene inactivation during human $T$ cell proliferation
}

\author{
Aida Gabdoulkhakova ${ }^{\text {a,b }}$, Gunnel Henriksson ${ }^{a}$, Nadezhda Avkhacheva ${ }^{a, b}$, Alexander \\ Sofin ${ }^{\mathrm{a}, \mathrm{b}}$, Anders Bredberg ${ }^{\mathrm{a}^{*}}$ \\ a Department of Laboratory Medicine, Section of Medical Microbiology, Lund University, \\ Malmo University Hospital, S-205 02 Malmo, Sweden \\ ${ }^{\mathrm{b}}$ Laboratory of Nerve Cell Biophysics, Institute of Cell Biophysics, Russian Academy of \\ Sciences, Pushchino, Moscow region, 142290 Russia
}

Running title: Lymphocyte proliferation and gene inactivation

Key words: T cell activation; DNA methylation; gene inactivation; PIG-A; HPRT

*Corresponding author

e-mail: anders.bredberg@med.lu.se 


\begin{abstract}
Caspase activation and degradation of DNA damage response factors occur during in vitro $\mathrm{T}$ cell proliferation, and an increased frequency of hypoxanthine-guanine phosphoribosyltransferase (HPRT)-negative variants have been reported in conditions associated with in vivo T cell proliferation. We have applied two human somatic cell mutation reporter assays, for the HPRT and phosphatidylinositol glycan class A (PIG-A) genes, to human T cells activated in vitro with anti-CD3 and anti-CD28. We demonstrate proliferation throughout 6 weeks of cultivation, and find that the frequency of variant cells phenotypically negative for HPRT and PIG-A, respectively, increases from $10^{-5}$ up to $10^{-3}$ $10^{-2}$. We also report preliminary evidence for low-density $\mathrm{CpG}$ methylation in the HPRT promoter suggesting that epigenetic modification may contribute to this markedly heightened rate of gene inactivation.
\end{abstract}




\section{Introduction}

Signs of DNA damage response (DDR) deficiency have been observed in cells undergoing rapid proliferation, including inactivation of the p16 cell cycle inhibitory gene in normal breast epithelia (Romanov et al. 2001; Sancar et al. 2004). Furthermore, lymphocyte proliferation is coupled with partial caspase activation leading to degradation of DDR factors (Alam et al. 1999; Chun et al. 2002; Miossec et al. 1997; Newton and Strasser 2003; Tong et al. 2001), and with production of DNA-damaging reactive oxygen species (ROS) (Hildeman et al. 2003; Martindale and Holbrook 2002). An elevated frequency of variant cells in conditions associated with strong lymphocyte activation has been revealed by the hypoxanthine-guanine phosphoribosyltransferase (HPRT) standard human mutation reporter assay (Albertini 2001; Ansari et al. 1995; Gmelig-Meylin et al. 1992). However, the mutation rate in proliferating lymphocytes may then have been underestimated, since activated T cells are highly susceptible to 'activation-induced' cell death (Abbas 1996; Hildeman et al. 2002; Hildeman et al. 2003), and may thus not survive the in vitro 1-2 weeks cloning step.

The present work was initiated to test if an increased mutation rate is one of the numerous changes, including activation of immune-response genes, that occur during lymphocyte proliferation (Chtanova et al. 2005). T cells were activated in vitro by engagement of CD3 and CD28, and then analysed during several weeks of growth for deficiency in HPRT and the glycosylphosphatidylinositol (GPI) membrane anchor protein (Araten et al. 1999; Takeda et al. 1993) using flow cytometry with no need for cell cloning. For both of these reporter assays we now demonstrate a more than hundred-fold rise in the fraction of variant T cells. Although DNA sequencing for determination of the mutational status of cloned variant cells was not performed, we provide preliminary evidence that gene promoter $\mathrm{CpG}$ methylation contributes to this high rate of gene inactivation during $\mathrm{T}$ cell proliferation. 


\section{Materials and methods}

Reagents The following antibodies were used: anti-CD28 (clone YTH 913.12), anticaspase 3 (AHP476, recognizing intact $32 \mathrm{kDa}$ and the $17 \mathrm{kDa}$, but not $11 \mathrm{kDa}$, fragment), anti-DFF (clone AHP433, recognizing the intact $45 \mathrm{kDa}$ form and two C-terminal approximately $10 \mathrm{kDa}$ and $30 \mathrm{kDa}$ fragments) (Liu et al. 1998), PE-anti-CD52 and negative controls (Serotec); FITC-anti-CD44, FITC-anti-CD18, PE-anti-CD59 and negative controls (Immunotech); anti-CD3 (clone UCHT1, BD Biosciences); anti-BrdU and its secondary FITC-conjugated antibody as well as secondary HRP-conjugated antibodies (DAKO). Interleukin-2 (IL-2) was from Roche, 5,6-carboxyfluorescein diacetate succinimidyl ester (CFSE) from Molecular Probes, phytohaemagglutinine (PHA) from Murex, 6-thioguanine (6TG) from Sigma.

T cell culture Peripheral blood mononuclear cells were isolated from venous blood of healthy donors and a patient with paroxysmal nocturnal haematuria $(\mathrm{PNH})$ by gradient centrifugation (Lymphoprep, Nycomed), and cultured at $10^{6}$ cells $/ \mathrm{ml}$ in $5 \% \mathrm{CO}_{2}$ at $37^{\circ} \mathrm{C}$. Cell density was kept at $<2 \times 10^{6}$ cells/ml by dilution with IL-2-containing medium as appropriate. PHA $(1 \mu \mathrm{g} / \mathrm{ml})$ or culture flasks pre-coated with anti-CD3/anti-CD28 (1:1 mixture of $10 \mu \mathrm{g} / \mathrm{ml}$ ) was used for stimulation. IL-2 at final concentration of $10 \mathrm{U} / \mathrm{ml}$ was added at day 3. After 2-4 weeks of culture, at signs of slowed growth and increased death, restimulation by transfer to a precoated (as above) flask was done.

Western blot Protein extracts were prepared and SDS gel electrophoresis and blotting was done as described (Sallmyr et al. 2001). ECL (Amersham-Pharmacia) and either X-ray film or a BioRad Personal Molecular Imager FX were used for detection of the peroxidaseconjugated secondary antibodies. 
Thymidine incorporation Cultured $\mathrm{T}$ cells were stimulated as described above and cultivated in a 96-well plate in triplicate in growth medium at $10^{6}$ cells $/ \mathrm{ml}$. At day 5 the wells were pulsed for $20 \mathrm{~h}$ with $\left[{ }^{3} \mathrm{H}\right]$-labeled thymidine (Amersham, $25 \mathrm{Ci} / \mathrm{mmol}, 0.5$ $\mu \mathrm{Ci} /$ well) and counted using a 1450 MicroBeta Trilux, Wallac.

CFSE staining CFSE analysis was done as described (Lyons and Parish 1994). This dye is deacetylated intracellularly to a non-diffusible fluorescent derivative which can be determined by flow cytometry. In brief, $5 \times 10^{6}$ of cells/well in 6-well plates were aliquoted in growth medium, incubated with CFSE $(1 \mu \mathrm{M})$ for $30 \mathrm{~min}$ at $37^{\circ} \mathrm{C}$, washed 3 times with PBS, and analysed by flow cytometry (FACSCalibur from BD). Each next-coming day cells from the next well were analysed.

GPI flow cytometry assay T cells were stained with FITC-conjugated anti-CD18 and antiCD44 and PE-conjugated anti-CD52 and anti-CD59, and then analysed by flow cytometry (Araten et al. 1999). In order to determine the location of viable cells lacking GPI protein, labeling was done with only the FITC-conjugated antibodies but omitting anti-CD52 and anti-CD59. In so doing, a region for cells lacking phosphatidylinositol glycan class A (PIGA) gene expression was defined (Fig. 2A). Data analysis and plotting were done using WinList (Verity Software, Topsham, ME).

HPRT flow cytometry assay A modified method for analysis of HPRT-deficiency with no cloning of mutant cells was used (Kotova and Grawe 2002). T cells were grown in the presence of $6 \mathrm{TG}$ during the final $20 \mathrm{~h}$, and BrdU was present at $10^{-5} \mathrm{M}$ during the last $6 \mathrm{~h}$. A nuclei preparation was incubated with anti-BrdU and a secondary FITC-conjugated antibody, and labeled with propidium iodide (PI). FL-1 (FITC) and FL-3 (PI) fluorescence 
signals were collected, and the doublet discrimination module (Cellquest software, BD) was used in order to exclude false positive events resulting from cell aggregates (by using puls width) or from dead cells (by using pulse height). The variant cell frequency (VF) was calculated as described (Kotova and Grawe 2002). For example, in Fig. 3, 6.5\% of the cells incubated with BrdU but without 6TG are located in late-S (dot plot region R3); total acquired events for cells with BrdU and 6TG = 1258849; number of BrdU-labeled cells in $\mathrm{R} 3=78$; the $\mathrm{LI}=78 / 1258849=6.19 \times 10^{-5}$; the VF is $6.5 \times 10^{-5} / 0.065=9.5 \times 10^{-4}$. Data analysis and plotting were done using WinList.

Bisulfite DNA sequencing DNA was bisulfite-modified using the EZ DNA MethylationGold Kit (Zymo Research). A promoter region was amplified by PCR as described below, the PCR product was cloned (TopoTA cloning kit, Invitrogen), and submitted to the local sequencing core facility for ABI sequencing (Applied Biosystems).

PCR Primers were designed based on the HPRT 5'-flanking regions given on the University of California at Santa Cruz website http://genome.ucsc.edu, to bind non-CpG sequences and give products irrespective of the template's $\mathrm{CpG}$ methylation status. Two forward primers binding to sequences 155 bp apart were used in separate PCR amplifications: 5'-GTTAGGAAAATGGAAGTTATAGGTA and 5'ATTGAGTTGGGAGGGAAAGG; for all clones the reverse primer was 5'CCATTTCCACCTTCTCTTCCCA. Cycling conditions were $95^{\circ} \mathrm{C}$ for $12 \mathrm{~min}$ followed by 40 cycles of $95^{\circ} \mathrm{C} 1 \mathrm{~min}, 58^{\circ} \mathrm{C} 1 \mathrm{~min} 30 \mathrm{sec}, 72^{\circ} \mathrm{C} 2 \mathrm{~min} 30 \mathrm{sec}$, and then $72^{\circ} \mathrm{C}$ for $10 \mathrm{~min}$. The $25 \mu \mathrm{l}$ reaction solution contained $0.2 \mu \mathrm{M}$ each primer, 0.1 unit Hotstar Taq polymerase (Qiagen), $1.5 \mathrm{mM} \mathrm{MgCl}_{2}, 200 \mu \mathrm{M}$ each dNTP and $2 \mu 1$ of the bisulfite-modified DNA. For all PCR reactions, only the bisulfite-modified sense strand was amplified, starting with the 
reverse primer binding to this sense strand, and the complementary molecule thus produced serving as template for the forward primer. 


\section{Results}

T cell activation and long-term proliferation with caspase 3 activation Similar DNA

synthesis activities, as measured by ${ }^{3} \mathrm{H}$-thymidine incorporation, were seen at culture day 6 in the presence of PHA or monoclonal antibodies to CD3 and CD28, but the total number of viable cells was slightly higher for the antibody combination, as compared with PHA (8.8and 6.5-fold increase, respectively). The fraction of dead cells, as determined by trypan blue dye exclusion, was lower for anti-CD3/anti-CD28 $(<2 \%$, and $10 \%$ for PHA). Cellular CFSE content has been shown to be reduced by a factor of two per cell division, permitting the tracking of at least five ensuing cell cycles. Already on the third day after in vitro stimulation, some cells presented with a reduced CFSE signal (left peak of Fig. 1A). The double peak pattern generated by brightly CFSE-positive day 0 cells (solid line on right side of Fig. 1A) was seen only at culture start, and may reflect the presence of many mononuclear cell types. Flow cytometry revealed minor fractions of CD19+ B cells and CD14+ monocytes at culture start, whereas from the end of the first week and onwards only CD3+ Tcells could be detected. The culture was again labelled with CFSE at day 9. Reduction of CFSE content was observed over the following days 10,11 and 12; demonstrating proliferation apparently in the entire viable population, and suggesting a generation time of approximately $24 \mathrm{~h}$ (Fig. 1B). At week 4 a halt in proliferation was indicated by the closely located peaks at days $22-$ 24 (Fig. 1C). This was seen in all cultures at between 2 and 4 weeks after stimulation. The right-side, high intensity peak seen at CFSE staining day 22 may reflect artefactual and strong binding of dye to aggregated material derived from dead cells, becoming lost at the ensuing dates. Proliferation was resumed after restimulation with anti-CD3/anti-CD28, with CFSE results at days 30-32 no different from the earlier weeks (Fig. 1D). Throughout the culture periods of 5-6 weeks viability was high with less than 2\% trypan blue non-excluding cells, except for 5-50\% dead cells during slowed growth. 
Partial activation of the apoptosis caspase cascade is a component of normal $\mathrm{T}$ cell activation (Newton and Strasser 2003). Stimulation with anti-CD3/anti-CD28 was accompanied by degradation of procaspase 3 into its active $17 \mathrm{kDa}$ fragment (Fig. 2E), but with no sign of formation of $<45 \mathrm{kDa}$ active DNA fragmentation factor (DFF) (Fig. 2F). The minor $17 \mathrm{kDa}$ caspase 3 band seen at culture start may reflect the in vivo activated HLA class II-positive T cells routinely seen (1-10\% of total T cells) in healthy donors. The intensity of the barely detectable bands corresponding to degraded DFF forms show intensity covariation with the intact form, and cannot be interpreted as DFF activation.

$P I G-A$ gene inactivation during proliferation $P I G-A$ gene inactivation leads to loss of the GPI membrane protein, acting as an anchor for a number of lymphocyte surface proteins, e.g. CD52 and CD59. T cells were labeled with antibodies to CD18/CD44 (but not with the antibodies to CD52/CD59) in order to identify the dot-plot location (R2) of cells lacking GPI-anchored CD52/CD59 but with normal expression of the GPI-independent CD18/CD44 (Fig. 2A). Results from representative experiments are included in Fig. 2A-D; showing a relatively low variant cell frequency at culture start $\left(<1 \times 10^{-4}\right.$ at day 0$)$ (Fig. 2B); to become markedly increased at culture day $10\left(47 \times 10^{-4}\right)$ (Fig. 2C); later to return to a lower level $\left(<0.1 \times 10^{-4}\right.$ at day 42) (Fig. 2D). Analysis of cells from a patient diagnosed with PNH verified the capacity of our method to detect $P I G$ - $A$-mutant cells, showing a large amount of CD52/CD59-negative lymphocytes (16\%) (results not shown). In another control experiment a normal donor lymphocyte sample was spiked with decreasing numbers of PNH lymphocytes, documenting the method's capacity to detect rare $P I G-A$ variant cells (Table 1). All the performed $\mathrm{T}$ cell cultures showed a peak in the frequency of GPI-negative cells during weeks $2-5$, as depicted by the plotting of all determinations made with $>10^{5}$ cells (Fig. 
$2 \mathrm{E})$. For two of the cultures analysed at $>2$ time points the documented increase amounted to a thousand-fold or higher, for example from a starting level of $0.04 \times 10^{-4}$ to $44 \times 10^{-4}$.

HPRT gene inactivation during proliferation Proliferating lymphocytes were incubated with 6TG for $20 \mathrm{~h}$ at culture end, and with the DNA-specific BrdU base analogue during the last 6 $\mathrm{h}$ of these $20 \mathrm{~h}$. Cell nuclei were stained with PI (to measure total DNA content) and with FITC-labeled anti-BrdU (to define cells located in S phase). Only cells in late S phase were scored, since some label may be incorporated by HPRT-positive cells into newly synthesized DNA in the presence of 6TG (Albertini 2001). A representative flow cytometry experiment is shown in Fig. 3. Approximately 10\% of the non-6TG-treated control cells were located in late $\mathrm{S}$ phase, as defined by the square R3 region of Fig. 3, left panel. In the presence of 6TG, lymphocytes from culture day 7 showed a relatively high frequency of late $\mathrm{S}$ phase, i.e. HPRT-negative cells $\left(9.5 \times 10^{-4}\right)$ (Fig. 3, middle panel). The majority of these events can be regarded to truly represent BrdU-incorporating cells. However, a control experiment in the absence of the BrdU base analogue also revealed some events in the R3 region, representing cells non-specifically labeled with FITC-anti-BrdU (Fig. 3, right panel). The true HPRTnegative variant cell frequency in Figure $3 \mathrm{~A}$ is therefore given by $9.5-2.7=6.8 \times 10^{-4}$. The starting point variant frequency could not be assessed for HPRT, due to the S phase basis of the method (for culture day 0 data, see the $P I G-A$ gene results). However, a decline was found at culture day 42, with no detectable HPRT-negative cells as determined by specific events in the late S phase gate. Cultures from two other healthy donors showed VF peaks of $17.2 \times 10^{-4}$ (at day 36) and $34.1 \times 10^{-4}$ (at day 23) (results not shown). For comparison it may be of interest to note that although fewer experiments were made with the HPRT method, and although no day 0 value could be obtained with $H P R T$, the results suggested a similar kinetic pattern as with GPI, as well as a similar gene inactivation frequency level. 
Analysis of CpG Methylation in the HPRT Promoter Region HPRT expression is regulated by a CpG-rich promoter (Holliday and To 2002; Kang et al. 2003). Due to the X chromosome location of HPRT and its house-keeping function, human cells in general carry one active allele. However, which CpGs are most important for the control of HPRT gene expression has not been clearly established. We have studied a $386 \mathrm{bp}$ region upstream of the coding sequence with a total of $39 \mathrm{CpG}$ sites and several transcription factor-binding motifs including four GGGCGG Sp1 sites. A gene regulatory function is further suggested by a division of this segment based on $\mathrm{CpG}$ site clusters. This reveals some subregions with a marked homology with the corresponding mouse sequence (up to $78 \%$, as compared with $25 \%$ in the most 5 , 120 bp portion) (Fig. 4). After DNA bisulfite-modification, the promoter region was PCR-amplified, cloned and sequenced. Two different upstream PCR primers were used, explaining why only 14 clones include results for the 5' $12 \mathrm{CpG}$ 's. More methylation was seen in the 12 low-homology subregion CpG's, as compared with CpG's 13-39 (highly significant, with chi-square 105.6), but with no significant difference between proliferating (28.7\%) and resting cells $(21.7 \%)$. The frequency of methylated CpGs in the high-homology segment (CpG's 13-39) in 11 clones analysed from proliferating T cells (3.0\%) was higher than in 11 clones from unstimulated cells $(1.3 \%)$; however, no statistic significance was reached (chi-square 1.3). Four methylated $\mathrm{CpG}$ sites (i.e. $44 \%$ of the total of 9) were detected in proliferating T cells within the highest homology (78\%) subregion representing only 4 of the total $27 \mathrm{CpG}$ sites $(=15 \%)$ and 23 of the total $266 \mathrm{bp}(=9 \%)$, indicating preferential seeding of methylation in gene-regulatory sequences during proliferation. 


\section{Discussion}

A generation time as short as $6 \mathrm{~h}$ is observed during the limited proliferation phase of human lymphocyte activation in vivo (Abbas and Lichtman 2003). It can be speculated that a restricted use of DNA damage responses such as cell cycle arrest confers a selective advantage, by reducing the time needed to build up clones of effector cells large enough for the host to survive a microbial attack. Danger for the host in terms of malignant transformation may then be negligible, since physiologic activation-induced cell death will follow as soon as immune effector mission has been completed (Hildeman et al. 2002).

In the present work we test the idea that reduced DDR combined with an increase in DNA damage during physiologic $\mathrm{T}$ cell activation will increase the basal mutation rate. A mutated cell is then probably strongly programmed for apoptosis and therefore may not get through a week-long in vitro cloning procedure, suggesting that the current HPRT methodology is unable to document an elevated mutation rate during $\mathrm{T}$ cell activation in vitro. Therefore, we have employed two recently published phenotypic flow cytometric methods for measurement of $H P R T$ and $P I G-A$ gene expression, with no need for cell cloning of mutants.

Our finding of up to a thousand-fold increase in variant cell frequency cannot be explained solely by the spontaneous mutation rate acting over many cell divisions. A simple calculation shows that the number of cell divisions occuring in our $\mathrm{T}$ cell cultures, in combination with the normal basal mutation rate during proliferation of $10^{-6} /$ cell/generation (Albertini 2001; Drake et al. 1998; Tomlinson et al. 1996), will cause less than a two-fold increase in mutation frequency. $\mathrm{M}_{\mathrm{t}}=1-(1-\mathrm{a})(1-\mathrm{b} / 2)^{\mathrm{t}}$, with $\mathrm{M}$, mutation frequency; $\mathrm{t}$, number of cell generations; a, $\mathrm{M}$ at culture start; $\mathrm{b}$, basal spontaneous mutation rate. For example, assuming a mutation frequency of $10^{-5}$ at culture start, the spontaneous mutation rate acting over 30 cell generations will yield a mutation frequency of $2.5 \times 10^{-5}$. Therefore, our data indicate a marked increase not only in mutation frequency but also in the rate of some mechanism of 
gene inactivation. It should be noted that no selective drug was present during our 6-week cultures, providing no basis for preferential outgrowth of preformed variant cells; in contrast, the CFSE data indicate that the majority of the T cells were proliferating. It can be speculated that the return at a late culture time point to a low variant level is due to a relatively marked apoptotic disposition of a strongly proliferative and mutated $\mathrm{T}$ cell subpopulation.

It is unlikely that our variant frequency data are artefactual and represent the non-viable fraction of cells constantly present in lymphocyte cultures. First, the trypan blue dye exclusion test showed no increase in cell death at culture time points with a high variant level. Second, all results were collected only from flow cytometry events presenting with normal light forward and side scattering, considered to be characteristics of viable cells. Third, and foremost, both assays require a cell to display signs of intact homeostasis for it to be scored as a variant; HPRT variants show diploid total DNA content and newly replicated DNA; GPI variants show normal cell surface density of two GPI-independent proteins, CD18 and CD44. However, we may possibly have somewhat under-estimated the true variant frequency, due to HPRT or GPI protein remaining at sufficiently high concentration in the T cells for a few generations after gene inactivation, for the cell to escape from becoming scored as a mutant. A gradual loss of GPI protein during the cell generations following the $P I G-A$ gene inactivation can also explain the flow cytometry dot plot "tail" shape of the GPIdeficient cells (Fig. 2C).

Can we point to any plausible cellular mechanism(s) for generation of the large populations of variant lymphocytes? DNA-damaging and potentially mutagenic ROS (Laval et al. 1997; Martindale and Holbrook 2002) are present at elevated quantities during cell proliferation, and they are implicated in the massive death of lymphocytes initiated after the effector phase (Hildeman et al. 2003). Another candidate mechanism is programmed down-regulation of genomic surveillance. This has been suggested to be a general feature of terminally 
differentiated cells (Nouspikel and Hanawalt 2002). and has been observed in rare HPRTnegative T cell clones (Albertini 2001; Finette et al. 2000). Among the DDR factors becoming degraded in activated $\mathrm{T}$ cells is poly(ADPribose) polymerase (PARP), named guardian of the genome and considered to require large ATP quantities for its polyadenylation during DNA single-strand break repair (de Murcia and Shall 2000). In addition, induction of mutagenic cellular factors may form part of such programming, including illegitimate expression of V(D)J recombinase (Lipkowitz et al. 1992; MacGregor et al. 1994; Meydan et al. 1998), and production of a highly mutagenic cytosine deaminase (Bhagwat 2004). The HPRT and $P I G-A$ reporter assays have been verified to truly reflect DNA mutations (Albertini 1999; Araten et al. 1999), but HPRT promoter CpG methylation can also lead to formation of HPRT variant cells (Holliday and To 2002), documenting epigenetic modification as a possible basis for our observation of HPRT deficient T cells. Although our epigenetic results revealed no signs of cells with a densely methylated HPRT promoter suggestive of gene silencing, it should be noted that our PCR cloning strategy was not sensitive enough to detect variant cell frequencies of 1/1000 or less. Recently two groups have presented evidence for a "seeding" two-step mechanism operating during epigenetic gene silencing (Stirzaker et al. 2004; Ushijima 2005). The first step involves low-density methylation in a high fraction of the cells, similar to that we have observed for HPRT, while the second step with high-density promoter methylation and gene inactivation occurs only in a few of the "seeded" cells. These reports support that our findings of sparse methylation may reflect a mechanism for gene silencing in activated T cells. Future work will be needed to decipher the molecular event(s) behind the extensive gene inactivation observed by us in proliferating T cells. 
Acknowledgements We thank Walter Bodmer for generously providing laboratory facilities for the DNA methylation experiments and for the statistic analyses; Kristian Riesbeck for advice on $\mathrm{T}$ cell activation protocol and Johan Bredberg for the mathematical formula. This work was supported by the Swedish Institute, the Swedish Cancer Society, ICRETT Fellowship from UICC Geneva, UMAS Hospital Cancer Foundation, Gunnar Nilsson Cancer Fund and the Greta och Johan Kock, Crafoord, Osterlund and King Gustav V:s 80year Funds.

The experiments performed comply with the current laws of the countries, i.e. Sweden and United Kingdom, in which the experiments were performed.

\section{Conflict of interest statement}

None declared 


\section{References}

Abbas AK (1996) Die and let live: eliminating dangerous lymphocytes. Cell, 84: 655-657

Abbas AK, Lichtman AH (eds) (2003) Cellular and Molecular Immunology (5th ed). WB Saunders Philadelphia

Alam A, Cohen LY, Aouad S, Sekaly RP Early activation of caspases during T lymphocyte stimulation results in selective substrate cleavage in nonapoptotic cells. (1999) J Exp Med 190: 1879-1890

Albertini RJ (2001) HPRT mutations in humans: biomarkers for mechanistic studies. Mutation Res 489: 1-16

Ansari AA, Mayne A, Sundstrom JB, Gravanis MB, Kanter K, Sell KW, Villinger F, Siu, CO, Herskowitz, A (1995) Circulation 92: 862-874

Araten DJ, Nafa K, Pakdeesuwan K, Luzzatto L (1999) Clonal populations of hematopoietic cells with paoxysmal nocturnal memoglobinuria genotype and phenotype are present in normal individuals. Proc Natl Acad Sci USA 96: 5209-5214

Bhagwat AS (2004) DNA-cytosine deaminases: from antibody maturation to antiviral defense. DNA Repair 3: 85-89

Chtanova T, Newton R, Liu SM, Weininger L, Young TR, Silva DG, Bertoni F, Rinaldi A, Chappaz S, Sallusto F (2005) Identification ofT cell-restricted genes, and sigantures for different $\mathrm{T}$ cell responses, using a comprehensive collection of microarray datasets. J Immunol 175: 7837-7847

Chun HJ , Zheng L, Ahmad M, Wang J, Speirs CK, Siegel RM, Dale JK, Puck J, Davis J, Hall CG, Skoda-Smith S, Atkinson TP, Strauss SE, Lenardo MJ (2002) Pleiotropic defects in lymphocyte activation caused by caspase- 8 mutations lead to human immunodeficiency. Nature 419: 95-399 
Drake JW, Charlesworth B, Charlesworth D, Crow JF (1998) Rates of spontaneous mutation. Genetics 148: 1667-1686

de Murcia G, Shall S (eds) (2000) From DNA damage and stress signalling to cell death. Poly ADP-ribosylation reactions. (5th ed) Oxford University Press Oxford

Finette BA, Homans AC, Albertini RJ (2000) Emergence of genetic instability in children treated for leukemia. Science 288: 514-517

Gmelig-Meyling F, Dawisha S, Steinberg AD (1992) Assessment of in vivo frequency of mutated T cells in patients with systemic lupus erythematosus. J Exp Med 175: 297-300

Hildeman DA, ZhuY, Mitchell TC, Kappler J, Marrack P (2002) Molecular mechanisms of activated T cell death in vivo. Curr Op Immunol 14: 354-359

Hildeman DA, Mitchell TC, Kappler J, Marrack P (2003) T cell apoptosis and reactive oxygen species. J Clin Invest 111: 575-581

Holliday R, Ho T (2002) DNA methylation and epigenetic inheritance. Methods 27: 179-183

Kang SL, Kiefer CM, Yang TP (2003) Role of the promoter in maintaining transcriptionally active chromatin structure and DNA methylation patterns in vivo. Mol Cell Biol 23: $4150-4161$

Kotova N, Grawe J (2002) Flow cytometric determination of HPRT-variants in human peripheral blood lymphocytes. Mutation Res 499: 63-71

Laval F, Wink DA, Laval J (1997) A discussion of mechanisms of NO genotoxicity: implication of inhibition of DNA repair proteins. Rev Physiol Biochem Pharmacol 131: $175-191$

Lipkowitz S, Garry VF, Kirsch IR (1992) Interlocus V-J recombination measures genomic instability in agriculture workers at risk for lymphoid malignancies. Proc Natl Acad Sci USA 89: 5301-5305 
Liu X, Zou H, Staughter C, Wang X (1997) DFF, a heterodimeric protein that functions downstream of caspase-3 to trigger DNA fragmentation during apoptosis. Cell 89: 175184

Lyons AB, Parish CR (1994) Determination of lymphocyte division by flow cytometry. J Immunol Meth 171:131-137

Martindale JL, Holbrook NJ Cellular response to oxidative stress: Signaling for suicide and survival. (2002) J Cell Physiol 192: 1-15

McGregor WG, Maher VM, McCormick JJ (1994) Kinds and locations of mutations induced in the hypoxanthine-guanine phosphoribosyltransferase gene of human T-lymphocytes by 1-nitrosopyrene, including those caused by V(D)J recombinase. Cancer Res 54: 4207-4213

Meydan D, Hellgren D, Lambert B (1998) Variations in the frequency of T-cell receptor beta/gamma-interlocus recombination in long-term cultures of non-irradiated and X- and gamma-irradiated human lymphocytes. Int J Radiat Biol 74: 697-703

Miossec C, Dutilleul V, Fassy F, Diu-Hercend A Evidence for CPP32 activation in the absence of apoptosis during T lymphocyte stimulation. (1997) J Biol Chem 272: 1345913462

Newton K, Strasser A (2003) Caspases signal not only apoptosis but also antigen-induced activation in cells of the immune system. Genes Dev 17: 819-825

Nouspikel T, Hanawalt PC (2002) DNA repair in terminally differentiated cells. DNA Repair 1: 59-75

Romanov SR, Kozakiewicz K, Holst CR, Stampfer MR, Haupt LM, Tlsty TD (2001) Normal human mammary epithelial cells spontaneously escape senescence and acquire genomic changes. Nature 409: 633-637

Sallmyr A, Henriksson G, Fukushima S, Bredberg A (2001) Ku protein in human T and B 
lymphocytes: full length functional form and signs of degradation. Biochim Biophys Acta 1538: $305-312$

Sancar A, Lindsey-Bolt LA, Unsal-Kacmaz K, Linn S (2004) Molecular mechanisms of mammalian DNA repair and the DNA damage checkpoints, Annu. Rev. Biochem. 73: $39-85$

Stirzaker C, Song JZ, Davidson B, Clark SJ (2004) Transcriptional gene silencing promotes DNA hypermethylation through a sequential change in chromatin modifications in cancer cells. Cancer Res 64: 3871-3877

Takeda J, Miyata T, Kawagoe K, Iida Y, Endo Y, Fujita T, Takahashi M, Kitani K, Kinoshita T (1993) Deficiency of the GPI anchor caused by a somatic mutation of the PIG-A gene in paroxysmal nocturnal hemoglobinuria. Cell 73: 703-711

Tomlinson IPM, Novelli MR, Bodmer WF (1996) The mutation rate and cancer. Proc Natl Acad Sci USA 93: 14800-14803

Tong WM, Cortes U, Wang ZQ. (2001) Poly(ADP-ribose) polymerase: a guardian angel protecting the genome and suppressing tumorigenesis. Biochim Biophys Acta 1552: 2737

Ushijima T (2005) Detection and interpretation of altered methylation patterns in cancer cells. Nat Rev Cancer 5: 223-231 


\section{Table 1}

Spiking of a normal lymphocyte sample with PNH mutant cells

$\%$ spiked cells (taken from PNH-patient sample)

\begin{tabular}{lcccccccc}
\cline { 2 - 7 } & 0 & 100 & 22 & 7 & 4 & 2 & 0.7 & 0.36 \\
\hline $\begin{array}{l}\text { Number of scored } \\
\text { PIG-A-negative cells }\end{array}$ & 7 & 4865 & 619 & 214 & 121 & 50 & 41 & 18 \\
$\begin{array}{l}\text { Observed frequency of } \\
\text { PIG-A-negative cells (\%) }\end{array}$ & 0.02 & 16.0 & 2.3 & 0.58 & 0.32 & 0.14 & 0.11 & 0.05 \\
$\begin{array}{l}\text { Expected frequency of } \\
\text { PIG-A-negative cells (\%) }\end{array}$ & n.a. & n.a. & 3.6 & 1.1 & 0.56 & 0.29 & 0.11 & 0.06 \\
\hline
\end{tabular}

n.a., not applicable 


\section{Figure legends}

Fig. 1 Partial caspase 3 activation and reduction in CFSE fluorescense intensity, verifying activation and long-term proliferation among a majority of the T lymphocytes. Cells were stimulated with anti-CD3/anti-CD28 and stained with CFSE at (A), day 0; (B), day 9; (C), day 22; (D), day 30. Solid lines denote the staining day and dotted lines the next-coming dates. Protein was extracted at the indicated culture times, immunoblotted with (E) anticaspase 3 (recognizing the full length $32 \mathrm{kDa}$ form and the active caspase $17 \mathrm{kDa}$ derivative) or $(\mathrm{F})$ anti-DFF (recognizing the full length $45 \mathrm{kDa}$ form and derivatives resulting from caspase cleavage). $6 \mathrm{TG}$ was added to the cultures of lanes 3 and 5 at $20 \mathrm{~h}$ before protein extraction (6TG inhibits proliferation of HPRT-expressing cells and is used for the detection of HPRT variants). The results are from representative cultures.

Fig. 2 PIG- $A$ gene inactivation during long-term $\mathrm{T}$ lymphocyte culture. The cells in (A) were labeled only with anti-CD18/anti-CD44, in order to define the location (R2) of cells totally lacking the GPI membrane anchor depending on $P I G-A$ expression. Labeling also with antiCD52/anti-CD59 was done at culture day 0 (B), day 10 (C) and day 42 (D). The number inserted to the left of R2 denotes the frequency $\left(\times 10^{-4}\right)$ of cells with GPI deficiency. (E), all available results from cultures with $>10^{5}$ scored cells, with the three curves representing cultures with analysis performed at $>2$ time points; the remaining seven analyses are from cultures with 1 or 2 time points (triangles). Note that Y-axis uses log scale.

Fig. 3 HPRT gene inactivation during long-term T lymphocyte culture. T cells were incubated with 6TG and/or BrdU as indicated at day 7 and then stained with PI (for total DNA content) and FITC-anti-BrdU (for DNA synthesis analysis). The left panel defines the 
location (R3) of late S phase cells. The middle panel shows HPRT-deficient cells proceeding into late S phase in the presence of 6TG. The right panel serves as control for cells nonspecifically binding FITC-anti-BrdU. VF is the frequency of HPRT-negative cells.

Fig. 4 Seeding of promoter methylation during T cell proliferation. HPRT promoter bisulfite DNA sequencing results for individual CpG sites are shown. Each line represents one PCR clone, and each of the $39 \mathrm{CpG}$ sites is shown as a circle with methylated CpG's highlighted in black. 14 of the clones were generated with the most upstream PCR forward primer, providing results for the 5'-located $12 \mathrm{CpG}$ 's. The base positions relative to the HPRT mRNA start site are shown. Promoter subregions are defined by closely located groups of $\mathrm{CpG}$ sites, revealing variation in human-mouse sequence homology, and suggesting that the upstream $12 \mathrm{CpG}$ site subregion (with 25\% homology) is less likely to be a gene expression regulatory sequence, as compared with the remaining $27 \mathrm{CpG}$ sites. 


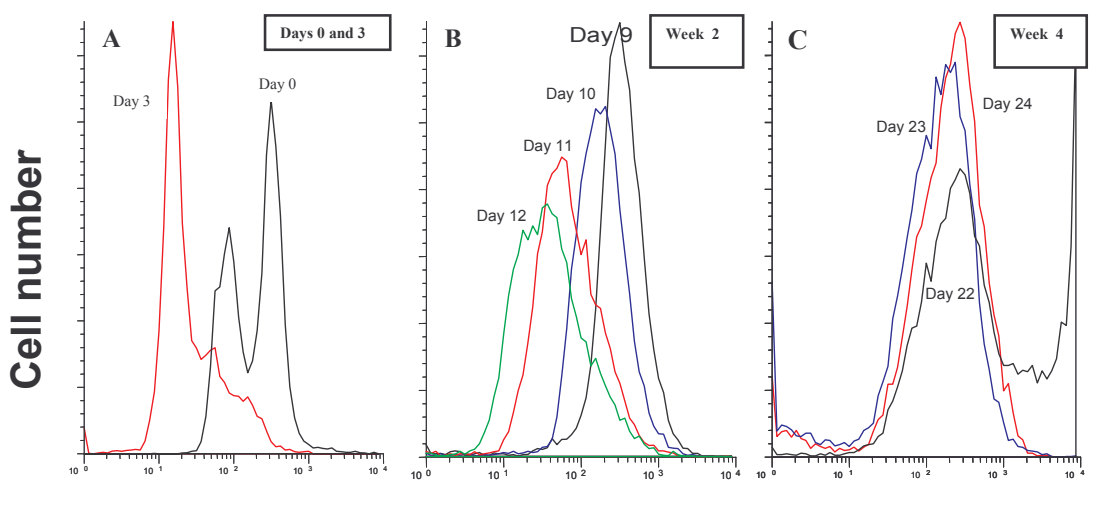

Fig. 1

\section{CFSE fluorescence intensity}

E

\section{Caspase 3}

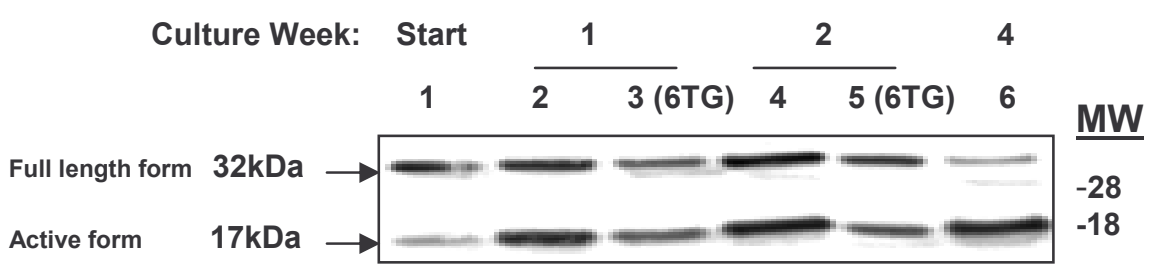

F

DFF

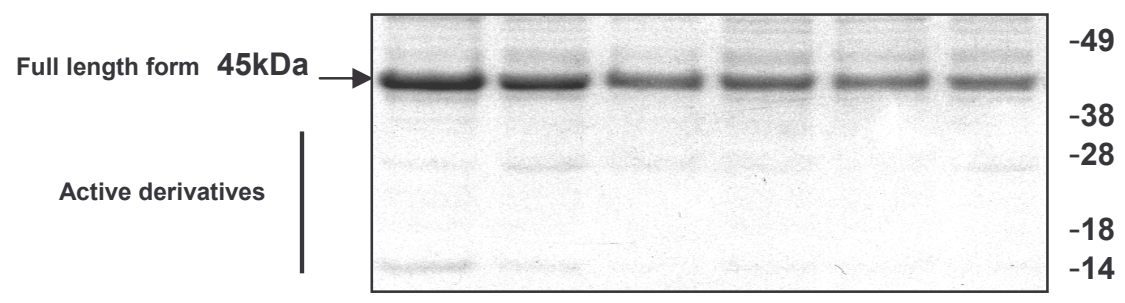


Fig. 2
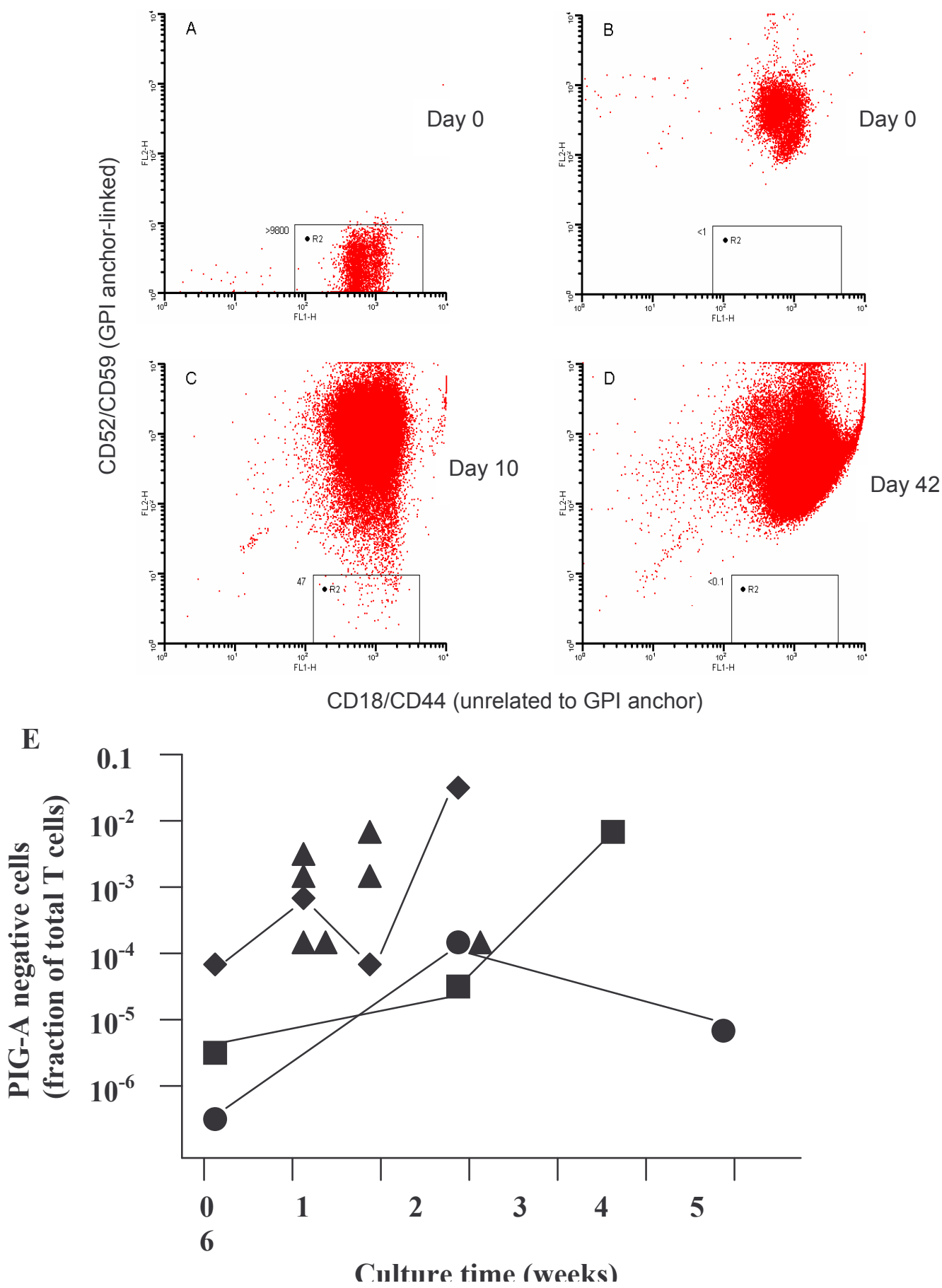
Fig. 3

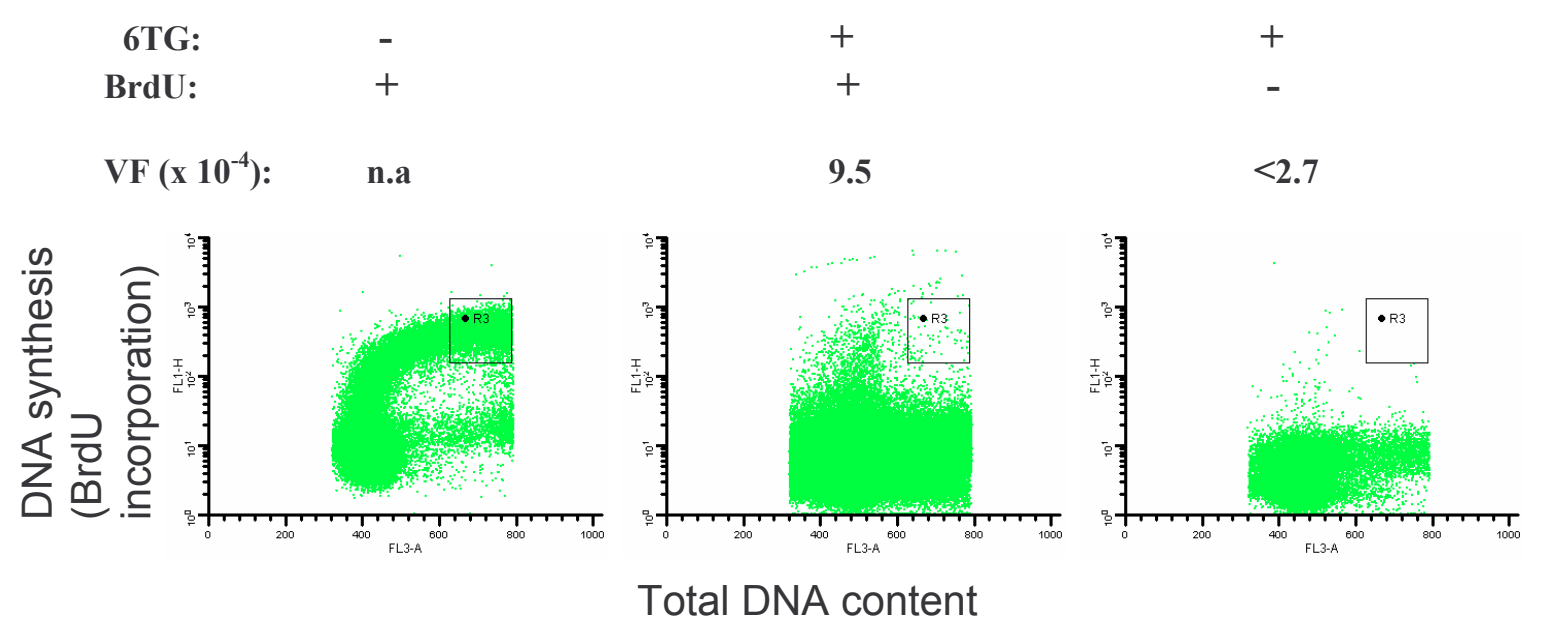


Fig. 4

Male unstimulated lymphocytes

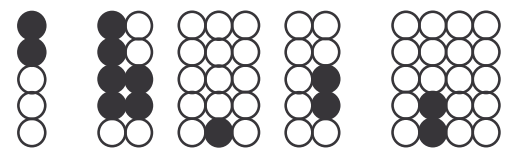

Male proliferating lymphocytes

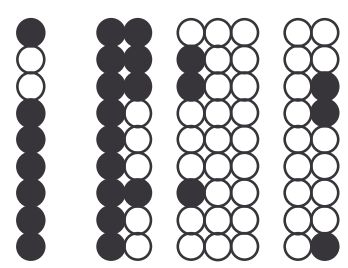

$-318$

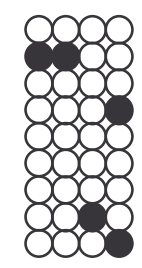

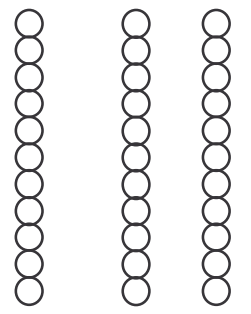

$\begin{array}{lll}8 & 8 & 8 \\ 8 & 8 & 8 \\ 8 & 8 & 8 \\ 8 & 8 & 8\end{array}$

$-198$
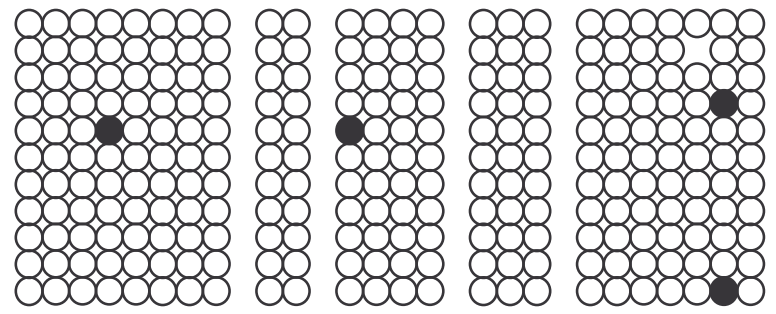

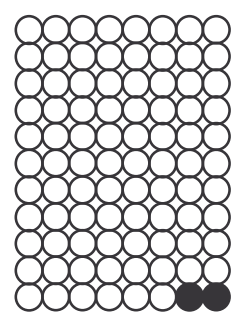

$-100$
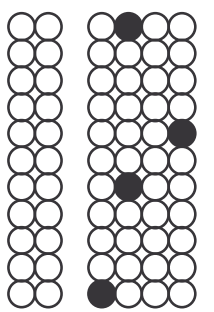

$-23$

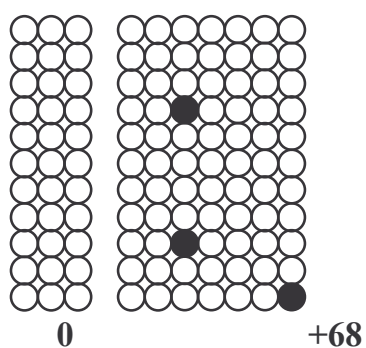

Promoter subregions with clustered CpG sites:

\begin{tabular}{|c|c|c|c|c|c|c|c|}
\hline Г & & & & & 7 & 7 & \\
\hline Homology: & $\begin{array}{l}25 \% \\
\text { (30/120 total bases) }\end{array}$ & $57 \%$ & $(56 / 98)$ & $62 \%$ & $\begin{array}{l}78 \% \\
(48 / 77)\end{array}$ & $\begin{array}{l}65 \% \\
(18 / 23)\end{array}$ & $(44 / 68)$ \\
\hline
\end{tabular}

CpG methylation (number of methylated CpG sites / number of total CpG sites): Unstimulated

lymphocytes $13 / 60=21.7 \%$

$\mathbf{0} / 33$

$1 / 110=0.9 \% \quad 1 / 44=2.3 \% \quad 2 / 110=1.8 \%$

Proliferating

lymphocytes $31 / 108=28.7 \%$

$\mathbf{0} / 33$

$2 / 110=1.8 \% \quad 4 / 44=9.1 \% \quad 3 / 110=2.7 \%$ 